\section{Dentoalveolar Evaluation of Lower Incisors by CBCT after Treatment with Herbst Appliance}

\author{
Camila Gerszewski1 ${ }^{1}$ Francielle Topolski ${ }^{1}$, Gisele M. Correr², Rodrigo A. P.
} Gomes $^{1}$, Nathaly D. Morais ${ }^{1}$, Alexandre Moro ${ }^{1,3}$
'Department of Orthodontics, Universidade Positivo, Curitiba, PR, Brazil ${ }^{2}$ Department of Restorative Dentistry, Universidade Positivo, Curitiba, PR, Brazil ${ }^{3}$ Department of Orthodontics, UFPR - Universidade Federal do Paraná, Curitiba, PR, Brazil

Correspondence: Alexandre Moro, Rua Prof. Pedro Viriato Parigot de Souza, 5300, 81280-330 Campo Comprido, Curitiba, PR, Brasil. Tel.: +55-41-3317-3180. e-mail: e-mail:

\begin{abstract}
This study aimed to evaluate the effects of the Herbst appliance on the proclination and protrusion of the lower incisors, and to verify if the device causes alveolar bone loss in the anterior region of the mandible. This is a retrospective study. The sample consisted of 35 individuals. The treatment group consisted of 22 individuals ( 8 girls and 14 boys; initial mean age of 8.2 years) who used the Cantilever Herbst appliance for a period of 12 months. The control group consisted of 13 individuals ( 3 girls and 10 boys; initial mean age of 8.9 years) who received no treatment and were followed up for a period of approximately 18 months. Cone-beam computed tomography scans were performed at the beginning and at the end of the observational period. The medullary bone thickness (MT), buccal cortical bone thickness (BCT), lingual cortical bone thickness (LCT), and lower incisors proclination and protrusion were evaluated. Data were submitted to statistical analysis (ANCOVA and Student's t-test) with a significance level of 5\%. There was no significant difference in MT, BCT, LCT and incisor proclination between groups. Incisor proclination increased in the treated group with no statistical significance. The treatment group showed a significant increase in the protrusion of the incisors $(p=0.02)$. The Herbst appliance promoted a small proclination and protrusion of the lower incisors, without relevant clinical implications. The Herbst appliance did not cause bone loss in the anterior region of the mandible during Class II treatment.
\end{abstract}

\section{alexandremoro@uol.com.br}

Key Words: Angle class II

malocclusion, incisor, tomography.

\section{Introduction}

Class II malocclusion is highly prevalent worldwide. Its etiology is multifactorial, being caused by skeletal or dental factors, or their combination. One of the common causes of Class II malocclusion is mandibular retrognathism (1). Among the various devices developed for the treatment of this malocclusion, the Herbst appliance is one of the most frequently used (2).

The Herbst appliance promotes a postural alteration in the mandible, positioning it anteriorly. It consists of a reciprocal intermaxillary anchor intraoral device. The device action of advancing the mandible causes an equal and opposite reaction in the upper arch. Thus, the appliance produces a forward force on the lower teeth (action) and a backward force on the upper teeth (reaction) (2). Some of the effects of the Herbst appliance are improvement in the maxillomandibular sagittal relationship, increase in condylar growth and mandibular length, protrusion and proclination of the lower incisors, retrusion and retroclination of the upper incisors (2-4).

Lower incisors protrusion, which often occurs during orthodontic treatment, is a concern for orthodontists (57). If the alveolar bone is narrow and the labial cortical bone is thin, incisors protrusion could lead to alveolar bone dehiscence and subsequent gingival recession (5).
Several studies evaluated the skeletal and dental effects of the Herbst appliance (2-4,8-11). However, few studies $(12,13)$ verified whether the device causes alveolar bone loss in the region of the lower incisors. Bié et al. (12) used a small sample, while Schwartz et al. (13) had no control group. In addition, the authors evaluated bone alterations smaller than the voxel size used $(0.4 \mathrm{~mm})$, which makes the evaluation unreliable. Bié et al. (12) did not observe alveolar bone loss caused by the Herbst appliance in the region of the lower incisors. Schwartz et al. (13) observed a small bone loss, without clinical significance. However, a study with a larger sample, a control group and using a smaller voxel size would be important.

The objective of this study was to evaluate the effects of the Herbst appliance on the protrusion and proclination of the lower incisors, as well as to verify if the device causes alveolar bone loss in the anterior region of the mandible. We tested the null hypothesis that the Herbst appliance does not cause increased proclination and protrusion of the lower incisors, nor does it promote alveolar bone loss in the anterior region of the mandible.

\section{Material and Methods}

The research is a retrospective study approved by the Ethics Committee of Universidade Positivo (175/2010). 
Patients had been evaluated or treated at the orthodontic clinic of Universidade Positivo and had routine CBCTs acquired for the purpose of the orthodontic or dental diagnosis and treatment planning. At the beginning of the observational period, all patients had at least $1 / 2$ molar Class II Division 1 malocclusion (cusp-to-cusp relationship), horizontal overjet greater than $4 \mathrm{~mm}$, mandibular retrognathism (evaluated clinically in the initial consultation by improvement of the facial profile when the patient was asked to advance the mandible) and convex facial profile. Patients who presented poor oral hygiene, active carious lesion, periodontal problems, previous orthodontic treatment, syndromes and dental agenesis were excluded. The sample consisted of 35 patients with an initial mean age of 8.5 years.

The treatment group consisted of 22 patients (8 girls and 14 boys; initial age varying from 7.9 to 8.6 years; initial mean age of 8.2 years) treated with the Cantilever Herbst appliance. The appliance had Rollo bands (American Orthodontics, Sheboygan, WI, USA) installed in the upper and lower first molars. The telescopic system used was the PMA (3M / ABZIL, São José do Rio Preto, SP, Brazil). For upper and lower anchoring, transpalatal and lingual arches were made with $1.1 \mathrm{~mm}$ steel wire. Supports were made on the occlusal surfaces of the second mandibular deciduous molars to sustain the lingual arch during the masticatory function. The initial mandibular advancement was up to an incisal end-to-end relationship. The appliance was used for 12 months. At the end of the treatment, the molar relationship was overcorrected by 2 to $3 \mathrm{~mm}$, that is, in mild Class III. The patients of the treated group had pre-treatment (T1) and post-treatment (T2) CBCTs acquired with a time interval of approximately 15 months.

The control group consisted of 13 patients ( 3 girls and 10 boys; initial age varying from 8.1 to 9.7 years; initial mean age of 8.9 years) who performed initial CBCTs (T1), and for different reasons - mainly unavailability of the parents or guardians to follow the patients in the consultations and difficulties related to the costs of the treatment - could not begin the treatment. These patients gradually returned spontaneously or were contacted again. They performed new CBCTs (T2) and were then referred for treatment. The time interval between the two CBCTs in the control group was approximately 18 months.

All CBCT scans were performed following the same radiological protocol, maintaining a standardized head position (Frankfurt plane parallel to the ground), scan time of $40 \mathrm{~s}$, field of view of $170 \times 170 \mathrm{~mm}$, and with the patient in maximal intercuspation position. The tomograph used was the i-Cat (Imaging Sciences International, Hatfield, Pa), 9140 model, with $115 / 230 \mathrm{Vac}, 10 \mathrm{~A} / 5 \mathrm{~A}$ and $50 / 60 \mathrm{~Hz}$ scanning parameters. The images were exported as DICOM (Digital Imaging and Communication in Medicine) universal format files, with voxel of $0.3 \mathrm{~mm}$.

The InVivo 5.0 software (Anatomage Inc., San Jose, CA, USA) was used to perform the linear and angular measurements. To standardize the position of the images in relation to the axial and sagittal planes, the bispinal line was used as a reference (Fig.s 1A and 1B). To standardize the position in relation to the coronal plane, the infraorbital line (13) (Fig. 1C) was used as reference.

With the image in the axial plane, a section was made passing through the amelocemental junction of the distobuccal portion of the first right lower molar. Using this section as reference, two axial sections were selected, passing 4.0 and $8.0 \mathrm{~mm}$ of the referred amelocemental junction. The section at $8.0 \mathrm{~mm}$ of the amelocemental junction was used to perform the following measurements (14) (Fig. 2A and 2B):

- Medullary bone thickness between the left lower central and lateral incisors (MT 31-32);

- Medullary bone thickness between the left and right
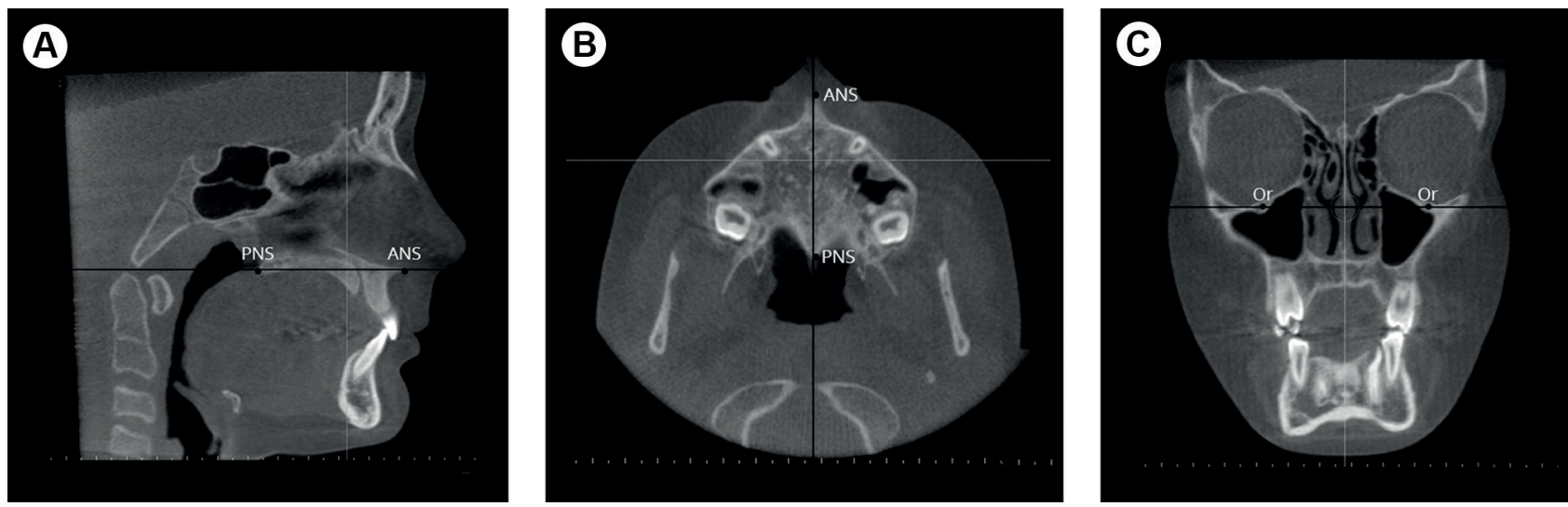

Figure 1. Standardized position of tomographic images. A: Sagittal plane. B: Axial plane. C: Coronal plane. a) ANS: anterior nasal spine; b) PNS: posterior nasal spine; c) Or: Orbital point. 
lower central incisors (MT 31-41);

- Medullary bone thickness between the right lower central and lateral incisors (MT 41-42);

- Buccal cortical bone thickness between left lower central and lateral incisors (BCT 31-32);

- Buccal cortical bone thickness between the left and the right lower central incisors (BCT 31-41);

- Buccal cortical bone thickness between the right lower central and lateral incisors (BCT 41-42);

- Lingual cortical bone thickness between the left lower central and lateral incisors (LCT 31-32);

- Lingual cortical bone thickness between the left and the right lower central incisors (LCT 31-41);

- Lingual cortical bone thickness between the right lower central and lateral incisors (LCT 41-42).

In the lateral cephalogram obtained from the CBCT scans, the following measurements were performed:

- Proclination of the lower central incisor, measured by the incisor mandibular plane angle (IMPA, angle between the mandibular plane and the long axis of the most proclined lower incisor) (4) (Fig. 2C);
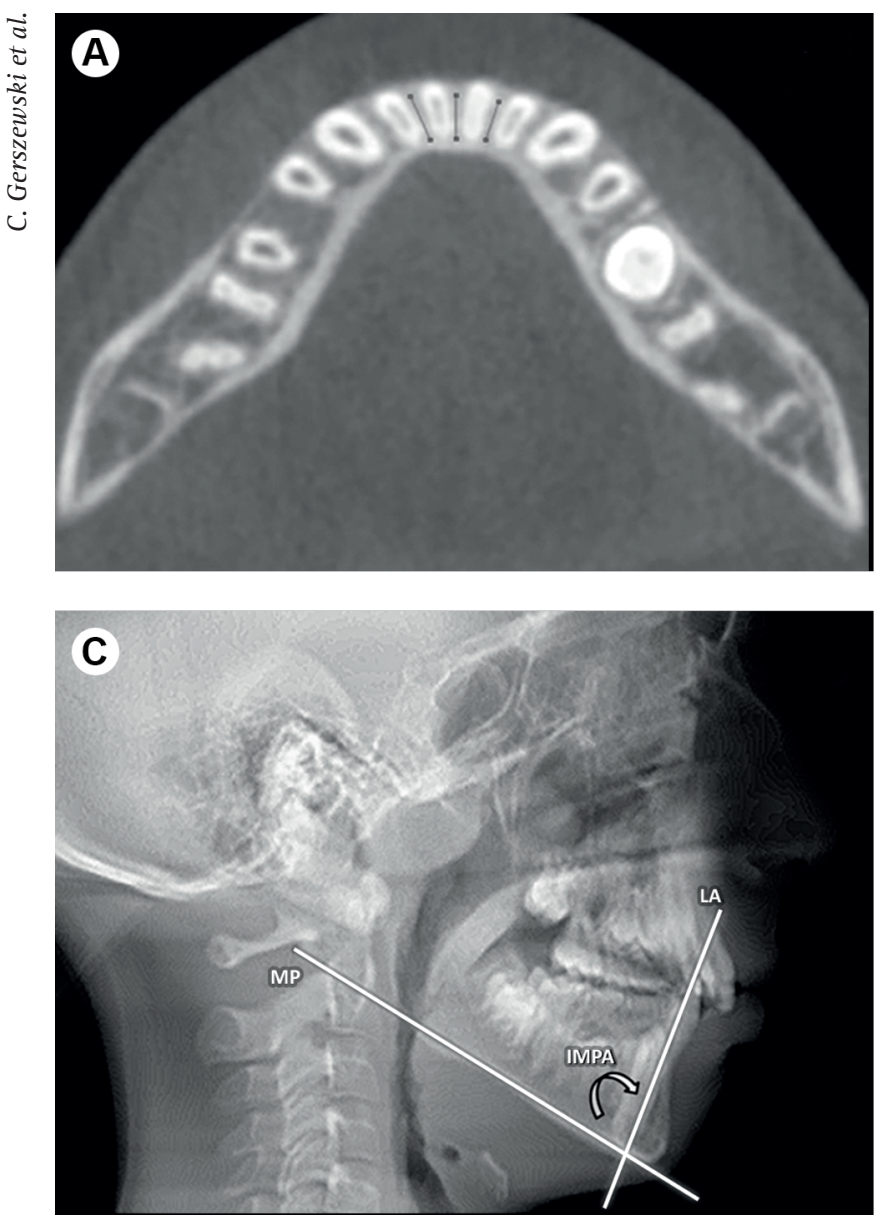

- Protrusion of the lower central incisor, li-PgPerp (linear measurement from the most prominent point of the vestibular face of the most protruded lower central incisor to a line perpendicular to the mandibular plane tangential to pogoniun) (4) (Fig. 2D).

Statistical analysis was performed with the Statistica program version 7.0 (Statsoft Inc., Tulsa, OK, USA). After verifying the normality of the data (Shapiro-Wilk, $p>0.05$ ), the differences between the means of the treatment and control groups were tested, adjusting the values for the Expected Growth Unit (EGU) (15). The covariance analysis model (ANCOVA) was used, considering the EGU as covariate. The null hypothesis was that there was no difference between the means of the treatment and control groups. Results with $p<0.05$ indicated a significant difference.

As boys and girls with varying ages were enrolled in the present study, and the follow-up time had different duration between groups, the sample was adjusted using EGU as a covariate in the ANCOVA. EGU is measured by the area of the gender-specific growth curves in which
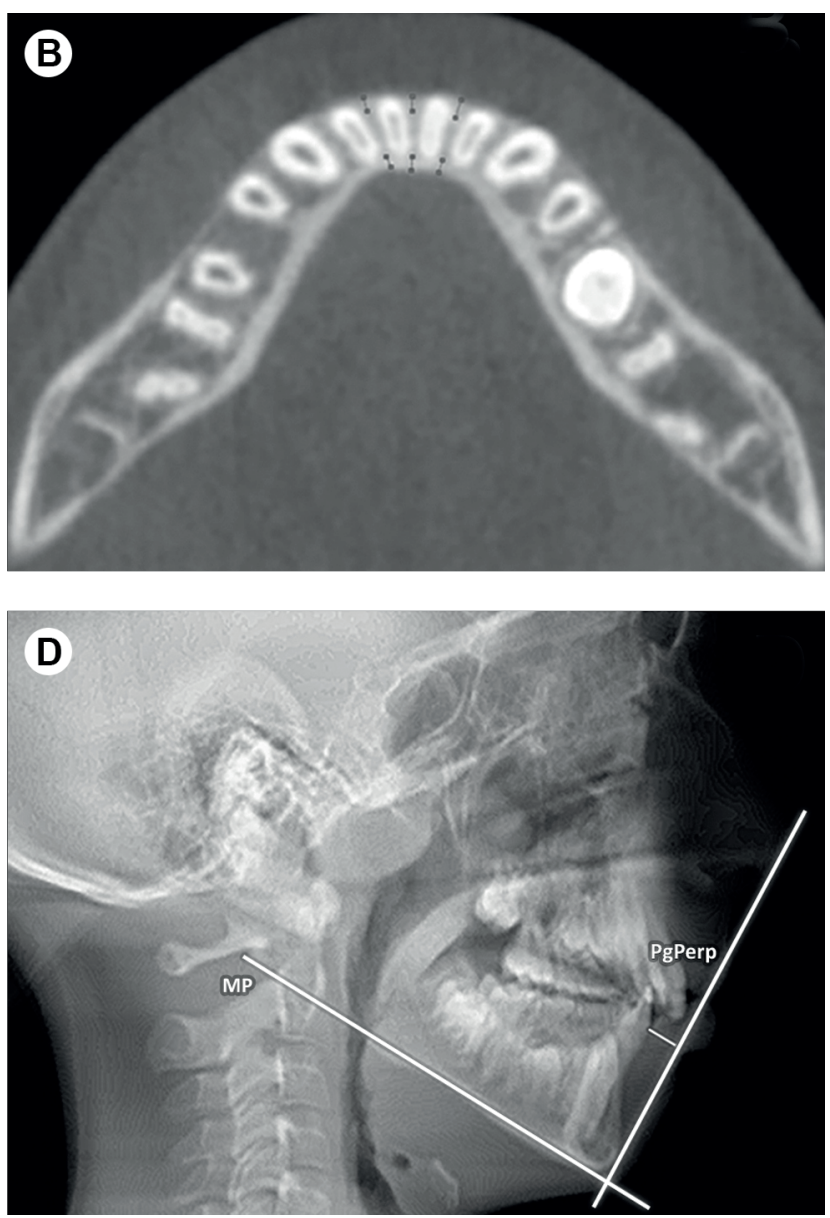

Figure 2. Linear and angular measurements performed on CBCT images. A: Bone marrow thickness in the lower incisors region. B: Buccal and lingual cortical bone thickness in the lower incisors region. C: Inclination of the lower central incisors. D: Protrusion of the lower central incisors. a) MP: mandibular plane; b) LA: long axis of the incisor; c) IMPA: incisor mandibular plane angle; d) PgPerp: line perpendicular to pogoniun. 
treatment takes place divided by the area of minimum prepubertal growth (9 to 10 years in girls, 11 to 12 in boys). EGU is an individualized estimate of the relative mandibular growth intensity - and the corresponding change in mandibular shape - that would be expected in an individual of a specific age and gender who was not treated orthodontically over a specific interval. EGU values were developed by Johnston (15) from facial growth curves.

The difference between the initial and final mean outcomes was also compared by paired Student's t-test. Significant differences were indicated by $p<0.05$.

To evaluate the intraexaminer systematic error, the measurements were performed repeatedly after 15 days in $10 \%$ of the sample, randomly selected. The paired Student t-test was applied. For random error, the calculation proposed by Dahlberg (16) was considered.

\section{Results}

The systematic intraexaminer error and random error were not statistically significant. Table 1 shows the mean \pm standard deviation of the initial and final measures of the different variables, as well as the $p$ values for the different statistical tests applied.

Table 1 shows that the variable MT 31-41 was significantly higher in the treatment group than in the control group in the initial $(p=0.02)$ and final evaluation $(p=0.02)$. No significant alteration was observed for medullary bone thickness, lingual cortical bone thickness, buccal cortical bone thickness, and incisors proclination.

Regarding incisors protrusion, a significant difference

Table 1. Mean \pm standard deviation of the outcomes

\begin{tabular}{|c|c|c|c|c|c|c|c|}
\hline Outcome & Group & $\mathrm{n}$ & Initial & Final & Difference & EGU & $\mathrm{p}^{*}$ \\
\hline \multirow{3}{*}{ MT 31-32 } & Control & 13 & $5.14 \pm 0.74$ & $5.26 \pm 0.75$ & $0.12 \pm 0.68$ & $1.86 \pm 0.27$ & 0.27 \\
\hline & Treatment & 22 & $5.59 \pm 0.99$ & $5.58 \pm 0.74$ & $-0.01 \pm 0.80$ & $1.32 \pm 0.52$ & 0.47 \\
\hline & $\mathrm{p}^{* * *}$ & & 0.16 & 0.16 & 0.75 & - & - \\
\hline \multirow{3}{*}{ MT 31-41 } & Control & 13 & $4.89 \pm 0.65$ & $5.14 \pm 0.70$ & $0.26 \pm 0.64$ & $1.86 \pm 0.27$ & 0.09 \\
\hline & Treatment & 22 & $5.76 \pm 1.14$ & $5.92 \pm 0.79$ & $0.16 \pm 0.90$ & $1.32 \pm 0.52$ & 0.20 \\
\hline & $\mathrm{p}^{* * *}$ & & 0.02 & 0.02 & 0.42 & - & - \\
\hline \multirow{3}{*}{ MT 41-42 } & Control & 13 & $5.06 \pm 0.58$ & $5.26 \pm 0.64$ & $0.20 \pm 0.54$ & $1.86 \pm 0.27$ & 0.10 \\
\hline & Treatment & 22 & $5.58 \pm 0.98$ & $5.71 \pm 0.93$ & $0.14 \pm 0.68$ & $1.32 \pm 0.52$ & 0.18 \\
\hline & $\mathrm{p}^{* *}$ & & 0.15 & 0.18 & 0.85 & - & - \\
\hline \multirow{2}{*}{ ВСТ $31-32$} & Control & 13 & $1.26 \pm 0.25$ & $1.29 \pm 0.28$ & $0.03 \pm 0.38$ & $1.86 \pm 0.27$ & 0.38 \\
\hline & Treatment & 22 & $1.39 \pm 0.39$ & $1.31 \pm 0.25$ & $-0.07 \pm 0.38$ & $1.32 \pm 0.52$ & 0.19 \\
\hline \multirow{4}{*}{ ВСТ $31-41$} & $\mathrm{p}^{* *}$ & & 0.61 & 0.82 & 0.54 & & \\
\hline & Control & 13 & $1.21 \pm 0.18$ & $1.16 \pm 0.20$ & $-0.05 \pm 0.24$ & $1.86 \pm 0.27$ & 0.24 \\
\hline & Treatment & 22 & $1.30 \pm 0.35$ & $1.36 \pm 0.34$ & $0.06 \pm 0.50$ & $1.32 \pm 0.52$ & 0.29 \\
\hline & $\mathrm{p}^{* * *}$ & & 0.29 & 0.15 & 0.77 & & \\
\hline \multirow{3}{*}{ BCT $41-42$} & Control & 13 & $1.24 \pm 0.14$ & $1.24 \pm 0.20$ & $0.00 \pm 0.27$ & $1.86 \pm 0.27$ & 0.48 \\
\hline & Treatment & 22 & $1.31 \pm 0.26$ & $1.33 \pm 0.27$ & $0.03 \pm 0.37$ & $1.32 \pm 0.52$ & 0.37 \\
\hline & $\mathrm{p}^{* *}$ & & 0.43 & 0.41 & 0.93 & & \\
\hline \multirow{3}{*}{ LCT $31-32$} & Control & 13 & $1.60 \pm 0.36$ & $1.66 \pm 0.36$ & $0.05 \pm 0.29$ & $1.86 \pm 0.27$ & 0.26 \\
\hline & Treatment & 22 & $1.60 \pm 0.37$ & $1.63 \pm 0.38$ & $0.02 \pm 0.23$ & $1.32 \pm 0.52$ & 0.33 \\
\hline & $\mathrm{p}^{* * *}$ & & 0.90 & 0.68 & 0.43 & & \\
\hline \multirow{3}{*}{ LCT $31-41$} & Control & 13 & $1.58 \pm 0.34$ & $1.61 \pm 0.28$ & $0.02 \pm 0.21$ & $1.86 \pm 0.27$ & 0.28 \\
\hline & Treatment & 22 & $1.62 \pm 0.38$ & $1.63 \pm 0.27$ & $0.01 \pm 0.25$ & $1.32 \pm 0.52$ & 0.42 \\
\hline & $\mathrm{p}^{* * *}$ & & 0.76 & 0.82 & 0.47 & & \\
\hline \multirow{3}{*}{ LCT $41-42$} & Control & 13 & $1.47 \pm 0.38$ & $1.51 \pm 0.25$ & $0.04 \pm 0.30$ & $1.86 \pm 0.27$ & 0.32 \\
\hline & Treatment & 22 & $1.56 \pm 0.34$ & $1.58 \pm 0.30$ & $0.02 \pm 0.27$ & $1.32 \pm 0.52$ & 0.35 \\
\hline & $\mathrm{p}^{* * *}$ & & 0.42 & 0.78 & 0.45 & & \\
\hline \multirow{3}{*}{ IMPA } & Control & 13 & $93.90 \pm 9.33$ & $90.36 \pm 11.46$ & $-3.54 \pm 12.60$ & $1.86 \pm 0.27$ & 0.17 \\
\hline & Treatment & 22 & $96.80 \pm 10.36$ & $100.00 \pm 8.33$ & $3.20 \pm 12.82$ & $1.32 \pm 0.52$ & 0.13 \\
\hline & $\mathrm{p}^{* *}$ & & 0.26 & 0.16 & 0.89 & & \\
\hline \multirow{3}{*}{ IiPgPerp } & Control & 13 & $4.89 \pm 2.18$ & $5.20 \pm 2.16$ & $0.31 \pm 1.18$ & $1.86 \pm 0.27$ & 0.18 \\
\hline & Treatment & 22 & $5.78 \pm 2.33$ & $4.67 \pm 2.8$ & $-1.11 \pm 1.41$ & $1.32 \pm 0.52$ & 0.001 \\
\hline & $\mathrm{p}^{* * *}$ & & 0.36 & 0.65 & 0.02 & & \\
\hline
\end{tabular}

*Paired Student t-test $(\mathrm{p}<0.05) .{ }^{* *}$ ANCOVA with EGU as covariate $(\mathrm{p}<0.05)$. 
was observed between the initial and final means of the treatment group $(p=0.001)$. A mean reduction of 0.31 $\mathrm{mm}$ was observed in the protrusion of lower incisors of the control group and a mean increase of $1.11 \mathrm{~mm}$ was found in the treatment group, a significant between-group difference $(p=0.02)$.

\section{Discussion}

In recent years, several modifications in the design of the Herbst appliance have been proposed to improve its effectiveness and reduce complications during use (17-18). In addition, much research has been done to assess the dento-skeletal effects of the appliance (2-4,8-11). However, few studies (12-13) have evaluated the adverse effects of the device on the alveolar bone in the lower incisors region, probably due to the difficulty of performing this evaluation with conventional radiographic techniques. The main limitation of conventional radiographs is that they provide two-dimensional images of three-dimensional structures, with consequent overlap of anatomical structures. With the incorporation of CBCT as a complementary exam in Orthodontics, the evaluations became more accurate and reliable, mainly due to the possibility of obtaining three$\Xi$ dimensional images (19).

A concern of using cone beam CBCT in alveolar bone studies relates to the size of the voxel for image acquisition (20-22). Patcas et al. (20) assessed the accuracy of CBCT scans with different resolutions $(0.125$ and $0.4 \mathrm{~mm})$ for linear measurements of the alveolar bone thickness around the lower incisors and found no significant difference between the two voxel sizes. Sun et al. (22) observed that measurements of alveolar bone height and thickness could be achieved from CBCT images with reproducibility varying from good to excellent. The authors also found that when bone thickness is greater than voxel size $(0.4 \mathrm{~mm})$, height measurements of alveolar bone tend to be overestimated by 0.5 to $1 \mathrm{~mm}$. On the other hand, when the voxel size is from 0.4 to $0.25 \mathrm{~mm}$, the accuracy of the linear measurements is improved. Sun et al. (22) reported that CBCT has diagnostic value for detecting bone dehiscence and fenestration. However, they observed that if the dehiscence vertical diameter is greater than $3 \mathrm{~mm}$ there is a systematic overestimation of the measurements. Overestimation was also found for fenestration measurement, with accuracy in only $20 \%$ of the cases. In the present study, the voxel used was $0.3 \mathrm{~mm}$. Therefore, the bone could be accurately assessed to a thickness of $0.3 \mathrm{~mm}$ (21). Considering that the thickness of the cortical bone evaluated was around 1 $\mathrm{mm}$, we believe that the measurements performed in this study were reliable.

In the present study, the groups were different in relation to the medullary bone thickness in the region between the lower central incisors. This parameter was significantly higher $(p=0.02)$ in the treatment group than in the control group, both in the initial and final evaluations. However, the difference between the initial and final means was not statistically significant, whether in the control group, in the treated group or in the comparison between the two groups. The medullary bone thickness, therefore, was not affected by the Herbst appliance, corroborating the findings of Bié et al. (12). Theoretically, the device could project the incisors and the buccal cortical could move forward increasing the medullary space. However, this was not observed.

In this study, no differences were observed in relation to the lingual and buccal cortical bone thickness with the use of the Herbst appliance. Similar results have been reported by Bié et al. (12) and Schwartz et al. (13). These results also corroborate the findings of Ruf et al. (6). The authors observed no correlation between lower incisors proclination induced by the Herbst appliance and gingival recession.

The thickness of the buccal and lingual cortical bone was measured in the region between the incisors. This made it easier to identify the limits of the bone plates, making measurements more reliable. Measurement in the region adjacent to each incisor would be problematic due to the difficulty of identifying the limit between the tooth and the bone plate, since the radiopacity of these structures are very similar. Additionally, if there was alveolar bone loss probably it would not occur at a specific point, but in an area, which would involve the space between the teeth. According to Garlock et al. (23) when a tooth is moved against a cortical bone, it tends to have its thickness reduced.

To evaluate the proclination of the incisors, IMPA was used and to evaluate the protrusion of the incisors, Ii-PgPerp was used. We chose to use these measures since they have already been used to evaluate the position of the incisors in other studies $(4,12)$.

There was an increase of $3.2^{\circ}$ in the proclination of the lower incisors in the treatment group, while in the control group there was a reduction of $3.5^{\circ}$ in this parameter. Therefore, the difference for the proclination of the lower incisors between groups was $6.7^{\circ}$. Corroborating other studies $(3,4,6)$, there was an increase in lower incisors proclination in patients treated with the Herbst appliance. However, this result was not statistically significant, possibly due to the variability of the sample. It should be noted that patients might have changes in IMPA without buccal vertical bone loss in the lower incisors (23).

There was a significant increase in the protrusion of the lower incisors in the treatment group. In the control group, a mean protrusion reduction of $0.31 \mathrm{~mm}$ was found while an increase of $1.11 \mathrm{~mm}$ was found in the treated group ( $p<0.05$ between group difference). The results of 
this study contradict the findings of Martin and Pancherz (7) who reported an increase of more than $3 \mathrm{~mm}$ in the protrusion of the lower incisors after treatment with the Herbst appliance. On the other hand, they corroborate the findings of Almeida et al. (3) $(1.2 \mathrm{~mm})$ and Moro et al. (4) $(1.4 \mathrm{~mm})$, who reported smaller increases.

Collectively, these studies show that the Herbst appliance does not promote such a large protrusion of the lower incisors that would require skeletal anchorage (24) to avoid the problem. On the other hand, leveling the lower teeth with a fixed appliance used in conjunction with the Herbst appliance should be avoided. Weschler and Pancherz (17), when comparing several forms of anchorage for the Herbst appliance in the lower arch, found that the use of the fixed appliance caused greater protrusion and proclination of the lower incisors. However, the use of the fixed appliance in the second stage of the treatment could reverse the proclination and protrusion of the lower incisors. For this purpose, a bracket prescription with additional lingual torque in the lower incisors could be used, as well as interproximal wear and incisors retraction.

This study showed that the Cantilever Herbst appliance produced a small protrusion of the lower incisors without, however, causing resorption of the buccal cortical bone. Although the incisal protrusion caused by the Herbst is small, it should be emphasized that the orthodontic literature is not clear about the extent that the mandibular buccal cortical bone can be remodeled (25). However, this study showed that the protrusion of $1 \mathrm{~mm}$ does not result in thickness loss of the buccal cortical bone.

This work has limitations, as periodontal parameters, such as periodontal biotype, plaque accumulation, and bleeding, which are potential factors for complications, were not included in the analysis. These parameters could not be included because of the retrospective nature of the study. Future prospective research, including periodontal clinical examination and follow-up, would be interesting.

In the treated group, the time interval between the two CBCTs was of approximately 15 months, while in the control group it was of approximately 18 months. In the treated group the CBCTs were performed as close as possible to the start and end of treatment. The patients' availability to perform the exams was reflected in a small variation in the interval between patients. In the control group, the interval between the exams was slightly longer and depended on the moment they returned to the treatment or were recontacted.

The null hypothesis tested in the research was partially rejected, since the Herbst appliance promoted increased proclination and protrusion of the lower incisors, but did not cause alveolar bone loss in the anterior region of the mandible.
Based on the results obtained, we can conclude that the Cantilever Herbst appliance used for 12 months to treat Class II malocclusion did not cause bone loss in the anterior region of the mandible. The treatment caused a mild protrusion of the lower incisors, with no relevant clinical implications.

\section{Resumo}

0 objetivo deste estudo foi avaliar os efeitos do aparelho de Herbst na proclinação e protrusão dos incisivos inferiores, bem como verificar se o aparelho causa perda óssea alveolar na região anterior da mandibula. Trata-se de um estudo retrospectivo. Foi utilizada uma amostra de 35 indivíduos. 0 grupo tratado foi formado por 22 individuos (8 meninas e 14 meninos; idade média inicial de 8,2 anos) que utilizaram o aparelho de Herbst com Cantilever por um período de 12 meses. 0 grupo controle foi composto por 13 individuos (3 meninas e 10 meninos; idade média inicial de 8,9 anos) que não receberam tratamento e foram acompanhados por um período de aproximadamente 18 meses. Exames de tomografia computadorizada de feixe cônico foram realizados no início e no final do período observacional. Foram avaliadas a espessura óssea medular (EM), espessura óssea cortical vestibular (ECV), espessura óssea cortical lingual (ECL), proclinação e protrusão dos incisivos inferiores. Os dados foram submetidos a análise estatística (ANCOVA e teste $t$ de Student) com nivel de significância de 5\%. Não houve alteração estatisticamente significativa na EM, ECV, ECL e proclinação dos incisivos entre os grupos. Houve um aumento na proclinação dos incisivos no grupo tratado, sem significância estatística. 0 grupo tratado apresentou aumento significativo na protrusão dos incisivos $(p=0,02)$. 0 aparelho de Herbst promoveu uma pequena proclinação e protrusão dos incisivos inferiores, sem implicações clínicas relevantes. 0 aparelho de Herbst não causou perda óssea na região anterior da mandibula durante o tratamento da Classe II.

\section{References}

1. Baccetti T, Franchi L, McNamara JA Jr, Tollaro I. Early dentofacial features of Class II malocclusion: a longitudinal study from the deciduous through the mixed dentition. Am J Orthod Dentofacial Orthop 1997;111:502-509.

2. Pancherz H. The effects, limitations, and long-term dentofacial adaptations to treatment with the Herbst appliance. Semin Orthod 1997;3:232-243.

3. Almeida MR, Henriques JFC, Almeida RR, Ursi W, McNamara Jr. JA. Short-term treatment effects produced by the Herbst appliance in the mixed dentition. Angle Orthod 2005;75:540-547.

4. Moro A, Janson G, de Freitas MR, Henriques JF, Petrelli NE, Lauris JP. Class II correction with the Cantilever Bite Jumper: a variant of the Herbst. Angle Orthod 2009;79;221-229.

5. Mazurova K, Kopp JP, Renkema AM, Pandis N, Katsaros C, Fudalej PS. Gingival recession in mandibular incisors and symphysis morphology a retrospective cohort study. Eur J Orthod 2018;40:185-192.

6. Ruf S, Hansen K, Pancherz H. Does orthodontic proclination of lower incisors in children and adolescents cause gingival recession? Am J Orthod Dentofac Orthop 1998;114:100-106.

7. Martin J, Pancherz H. Mandibular incisor position changes in relation to amount of bite jumping during Herbst/multibracket appliance treatment: a radiographic-cephalometric study. Am J Orthod Dentofacial Orthop 2009;136:44-51.

8. LeCornu M, Cevidanes LH, Zhu H, Wu CD, Larson B, Nguyen T. Threedimensional treatment outcomes in Class II patients treated with the Herbst appliance: a pilot study. Am J Orthod Dentofacial Orthop 2013;144:818-830.

9. Rego M, Thiesen G, Marchioro E, Silva Filho O, Rizzatto S. Cephalometric study of the early treatment of Class II division 1 malocclusion with the Herbst appliance: sagittal skeletal alterations. R Dental Press Ortodon Ortop Facial 2005;10:120-140. 
10. Franchi L, Baccetti T, McNamara Jr. JA. Treatment and posttreatment effects of acrylic splint Herbst appliance therapy. Am J Orthod Dentofacial Orthop 1999;115:429-438.

11. Souki B, Vilefort PLC, Oliveira DD, Andrade Jr. I, Ruellas AC, Yatabe MS et al. Three-dimensional skeletal mandibular changes associated with Herbst appliance treatment. Orthod Craniofac Res 2017;20:111-118.

12. Bié MDD, Moro A, Moresca R, Correr GM, Losso EM, Gomes RAP. Computed Tomographic evaluation of a young adult treated with the Herbst appliance. Orthod Sci Pract 2013;6:33-40.

13. Schwartz JP, Raveli TB, Schwartz-Filho HO, Raveli DB. Changes in alveolar bone support induced by the Herbst appliance: a tomographic evaluation. Dental Press J Orthod 2016;21:95-101.

14. Ferreira MC, Garib DG, Cotrim-Ferreira F. Method standardization of buccal and palatal arch bone plate measurement using cone beam computed tomography. Dental Press J Orthod 2010;15:49e1-49e7.

15. Johnston LE Jr. Growth and the Class II patient: rendering unto Caesar. Semin Orthod 1998;4:59-62.

16. Houston WJB. The analysis of errors in orthodontic measurements. Am J Orthod 1983;83:382-390.

17. Weschler D., Pancherz H. Efficiency of three mandibular anchorage forms in Herbst treatment: a cephalometric investigation. Angle Orthod 2004;75:23-27.

18. Silva JFE, Gerszewski C, Moresca RC, Correr GM, Flores-Mir C, Moro A. Retrospective study of clinical complications during orthodontic treatment with either a removable mandibular acrylic splint Herbst or with a cantilever Herbst. Angle Orthod 2014;85:64-71.

19. Capelozza Filho L, Fattori L, Maltagliati LA. A new method to evaluate teeth tipping using computerized tomography. R Dental Press Ortodon Ortop Facial 2005;10:23-29.

20. Patcas R, Müller L, Ullrich 0, Peltomäki T. Accuracy of cone-beam computed tomography at different resolutions assessed on the bony covering of the mandibular anterior teeth. Am J Orthod Dentofacial Orthop 2012;141:41-50.

21. Sun Z, Smith T, Kortam S, Kim DG, Tee BC, Fields H. Effect of bone thickness on alveolar bone-height measurements from cone-beam computed tomography images. Am J Orthod Dentofacial Orthop 2011;139:117-127.

22. Sun L, Zhang L, Shen G, Wang B, Fang B. Accuracy of cone-beam computed tomography in detecting alveolar bone dehiscences and fenestrations. Am J Orthod Dentofacial Orthop 2015;147:313-323.

23. Garlock DT, Buschang PH, Araujo EA, Behrents RG, Kim KB. Evaluation of marginal alveolar bone in the anterior mandible with pretreatment and posttreatment computed tomography in nonextraction patients. Am J Orthod Dentofacial Orthop 2016;149:192-201.

24. Manni A, Mutinelli S, Pasini M, Mazzotta L, Cozzani M. Herbst appliance anchored to miniscrews with 2 types of ligation: effectiveness in skeletal Class II treatment. Am J Orthod Dentofacial Orthop 2016;149:871-880.

25. Masella RS, Meister M. Current concepts in the biology of orthodontic tooth movement. Am J Orthod Dentofacial Orthop 2006;129:458-468.

Received February 23, 2018 Accepted October 10, 2018 